\title{
Investigation and Analysis on the Physique Tests of Adult Males and Adult Females (Aged 20-59) in Xi'an 2010
}

\author{
Yang Xin \\ Physical Education Department, Xi'an University of Science and Technology,Xi' an, 710054 China \\ xinyang@guigu.org
}

\begin{abstract}
This paper makes investigation and analysis on the physical fitness monitoring of 2586 adult males and adult females in Xi'an City, utilizing the literature and material method, questionnaire survey method and mathematical statistics method. The results show as the followings: 1 . there is no apparent differences on the cognition conditions of national physical fitness surveillance between adult males and adult females in Shaanxi Province. 2. There are certain correlations between the three of educational level, working condition and weekly work hours of the adult males and females in Shaanxi Province. 3. There are no apparent differences on the daily life circumstances between adult males and adult females in Shaanxi Province. However, there are apparent differences on the leisure time spending. 4 . When the adult males and females in Shaanxi Province take part in the physical exercises, the weekly exercise time and times of the males are higher than those of the females. 5. The destination selections for adult males and females in Shaanxi Province to take part in exercises are basically consistent. However, there is a little difference on choice preferences of physical exercise events. The target is to get to know the physical quality status of adult males and females in Shaanxi Province. Enrich the national physical fitness monitoring system and the database of Shaanxi Province, which offers scientific base for the implementation of national fitness plan.
\end{abstract}

Keywords: Adult; physical fitness; investigation and analysis

\section{INTRODUCTION}

Outline for National Fitness Plan (Short as Outline) is a trans-century project. After all, China has fully demonstrated its sporting prowess in recent Olympics, finishing in the top three of the medal standings. In 2010 the Shaanxi Province has make the physical quality monitoring.
First hand materials and data are obtained. Now the testing results are analyzed.

\section{Research Objects and Methods}

\subsection{Research Objects.}

2586 effective people have been chosen. They are adults aging 20-39 with healthy body and no apparent diseases. There are 1616 males and 970 females. The amount of the samples and the grouping are shown as the followings:

According to the ages and the testing projects, two groups are divided. Group A is from 20-39 and Group B is from 40-59. Every five years are determined to be an age period. There are respectively 89 and 52 males and females aging 20-24. There are respectively 188 and 86 males and females aging 25-29. There are respectively 204 and 116 males and females aging 30-34. There are respectively 256 and 168 males and females aging 35-39. There are respectively 332 and 228 males and females aging 40-44. There are respectively 282 and 175 males and females aging 45-49. There are respectively 192 and 113 males and females aging 50-54. There are respectively 73 and 32 males and females aging 55-59.

\subsection{Research Methods.}

1) Physical fitness measurement method: adopting "national physical fitness measurement standard".

2) Data treatment method: all data have been dealt with by spss 10.0 statistics software.

3) Comparison analysis method

\section{Results and Analysis}

\subsection{Body shape.}

Among the physical fitness investigation of the adults, the body shape indexes mainly refer to height and weight. The height and weight of the males and females in Xi'an City are normal, which can be shown in Fig. 1 and Table 1. 
Table 1: the average height and weight of men and women in different age periods and the standard deviation

\begin{tabular}{|c|c|c|c|c|c|c|c|c|c|}
\hline \multirow{2}{*}{$\begin{array}{c}\text { index } \\
\text { es }\end{array}$} & \multirow{2}{*}{$\begin{array}{l}\text { gend } \\
\text { er }\end{array}$} & \multicolumn{8}{|c|}{ Age periods } \\
\hline & & $20-24$ & $25-29$ & $30-34$ & $35-39$ & $40-44$ & $45-49$ & $50-54$ & $55-59$ \\
\hline heigh & M & $170.8 \pm 6.1$ & $169.9 \pm 6.6$ & $170.0 \pm 4.8$ & $169.3 \pm 5.4$ & $169.5 \pm 5.3$ & $169.1 \pm 5.5$ & $169.1 \pm 5.3$ & $167.7 \pm 5.8$ \\
\hline $\begin{array}{c}\text { ts } \\
(\mathrm{cm})\end{array}$ & W & $159.1 \pm 5.7$ & $159.9 \pm 6.3$ & $158.1 \pm 5.5$ & $158.3 \pm 5.4$ & $159.1 \pm 5.3$ & $158.5 \pm 5.3$ & $157.3 \pm 4.8$ & $156.1 \pm 5.0$ \\
\hline Weig & M & $66.9 \pm 10.6$ & $68.1 \pm 11.0$ & $70.5 \pm 10.0$ & $71.6 \pm 9.9$ & $74.3 \pm 10.0$ & $73.2 \pm 9.8$ & $73.6 \pm 8.6$ & $70.1 \pm 8.7$ \\
\hline$(\mathrm{kg})$ & W & $52.4 \pm 7.1$ & $55.2 \pm 6.9$ & $55.1 \pm 6.9$ & $57.7 \pm 7.4$ & $59.7 \pm 7.3$ & $61.0 \pm 7.8$ & $60.0 \pm 6.8$ & $61.6 \pm 7.7$ \\
\hline
\end{tabular}

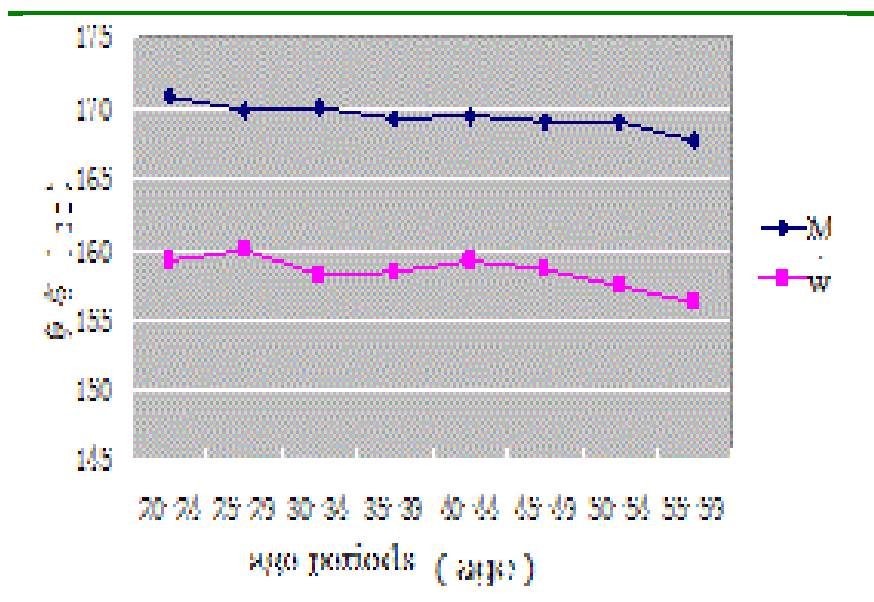

Fig.1 comparisons on average heights of men and women in different age periods;

\subsection{Functions.}

According to the standardization, the vital capacity belongs to level 3 .

A step-index profile is a refractive index profile characterized by a uniform refractive index within the core and a sharp decrease in refractive index at the core-cladding

Table 2: the average vital capacity, step-index of men and women in different age periods and standardization derivation

\begin{tabular}{|c|c|c|c|c|c|c|c|c|c|}
\hline inde & gend & & & & Age peri & ds (age) & & & \\
\hline $\mathrm{x}$ & er & $20-24$ & $25-29$ & $30-34$ & $35-39$ & $40-44$ & $45-49$ & $50-54$ & $55-59$ \\
\hline $\begin{array}{l}\text { Vital } \\
\text { capac }\end{array}$ & M & 3955.7 & 3834.7 & 3725.9 & 3546.9 & 3437.7 & 3301.8 & 3225.6 & 2998.0 \\
\hline ) ml & & \pm 645.6 & \pm 668.3 & \pm 693.5 & \pm 613.7 & \pm 678.4 & \pm 609.3 & \pm 658.7 & \pm 605.4 \\
\hline & W & 2586.2 & 2655.9 & 2501.4 & 2454.8 & 2338.5 & 2160.2 & 2057.4 & 1918.1 \\
\hline & & \pm 585.8 & \pm 793.8 & \pm 639.8 & \pm 586.2 & \pm 576.1 & \pm 517.6 & \pm 594.6 & \pm 597.0 \\
\hline Step & M & $57.9 \pm 9.5$ & $55.3 \pm 7.7$ & $55.3 \pm 7.8$ & $54.6 \pm 7.3$ & $54.0 \pm 7.6$ & $54.8 \pm 8.0$ & $55.1 \pm 9.0$ & $55.7 \pm 9.5$ \\
\hline inde & W & $60.3 \pm 10.5$ & $58.8 \pm 8.3$ & $58.6 \pm 9.0$ & $59.7 \pm 8.1$ & $58.9 \pm 9.5$ & $59.8 \pm 9.5$ & $60.7 \pm 8.7$ & $60.6 \pm 9.7$ \\
\hline
\end{tabular}




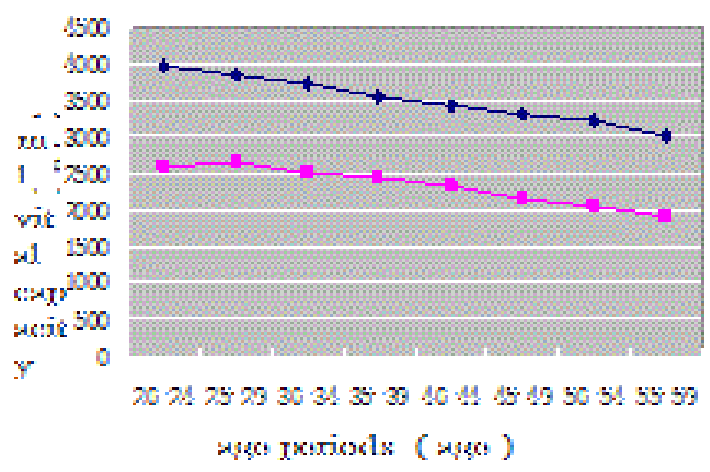

Fig. 3: comparisons of average vital capacity of men and women in different ages;

\subsection{Qualities.}

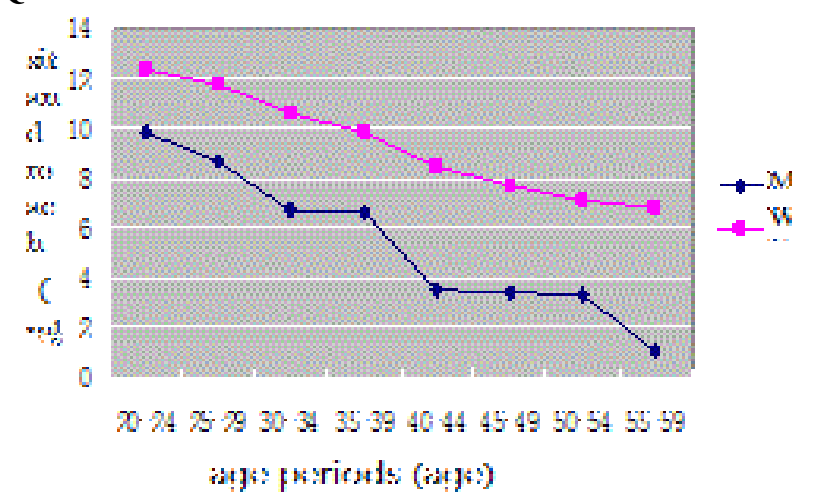

Fig. 5: Comparisons of sit-and-reach of men and women in different ages

Formulae were derived to predict genetic response under various selection schemes assuming an infinitesimal model. Account was taken of genetic drift, inbreeding depression, common environmental variance, and both initial segregating variance within families and mutational variance.

Grip strength is the force applied by the hand to pull on or suspend from objects and is a specific part of hand

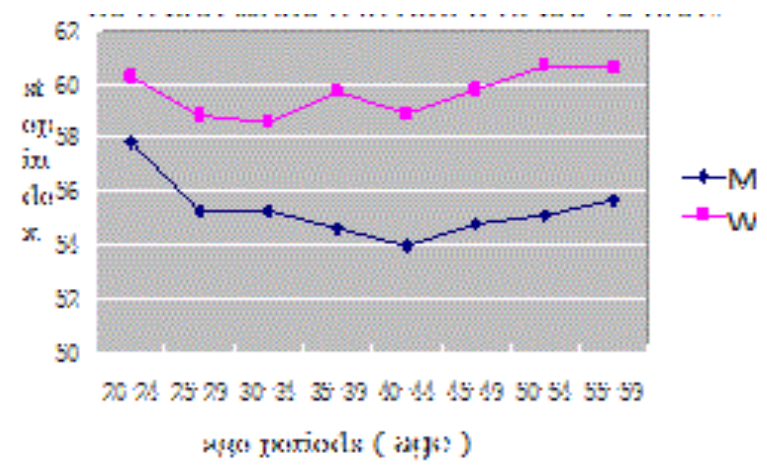

Fig. 4: Comparisons of average step indexes of man and women in different ages

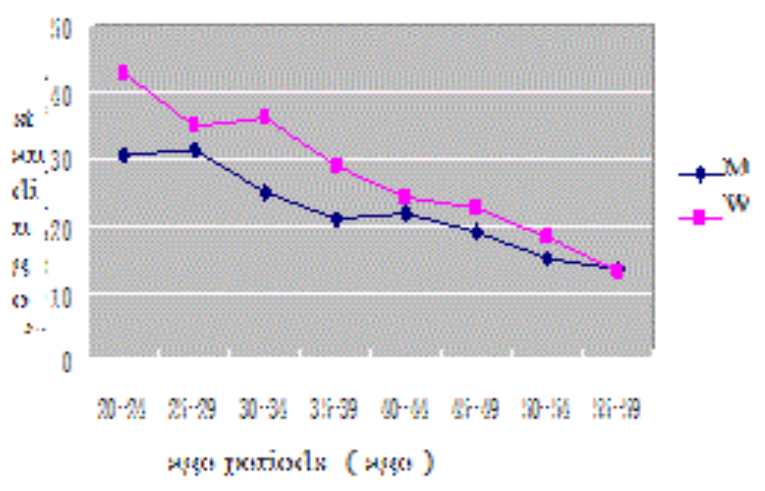

Fig.6: Comparisons of standing on one foot of men and women in different ages

strength. Optimum-sized objects permit the hand to wrap around a cylindrical shape with a diameter from one to three inches. Stair rails are an example of where shape and diameter are critical for proper grip in case of a fall. Other grip strengths that have been studied are the hammer and other hand tools. 
Table 3: the average indexes of men and women in different ages and standardization derivation.

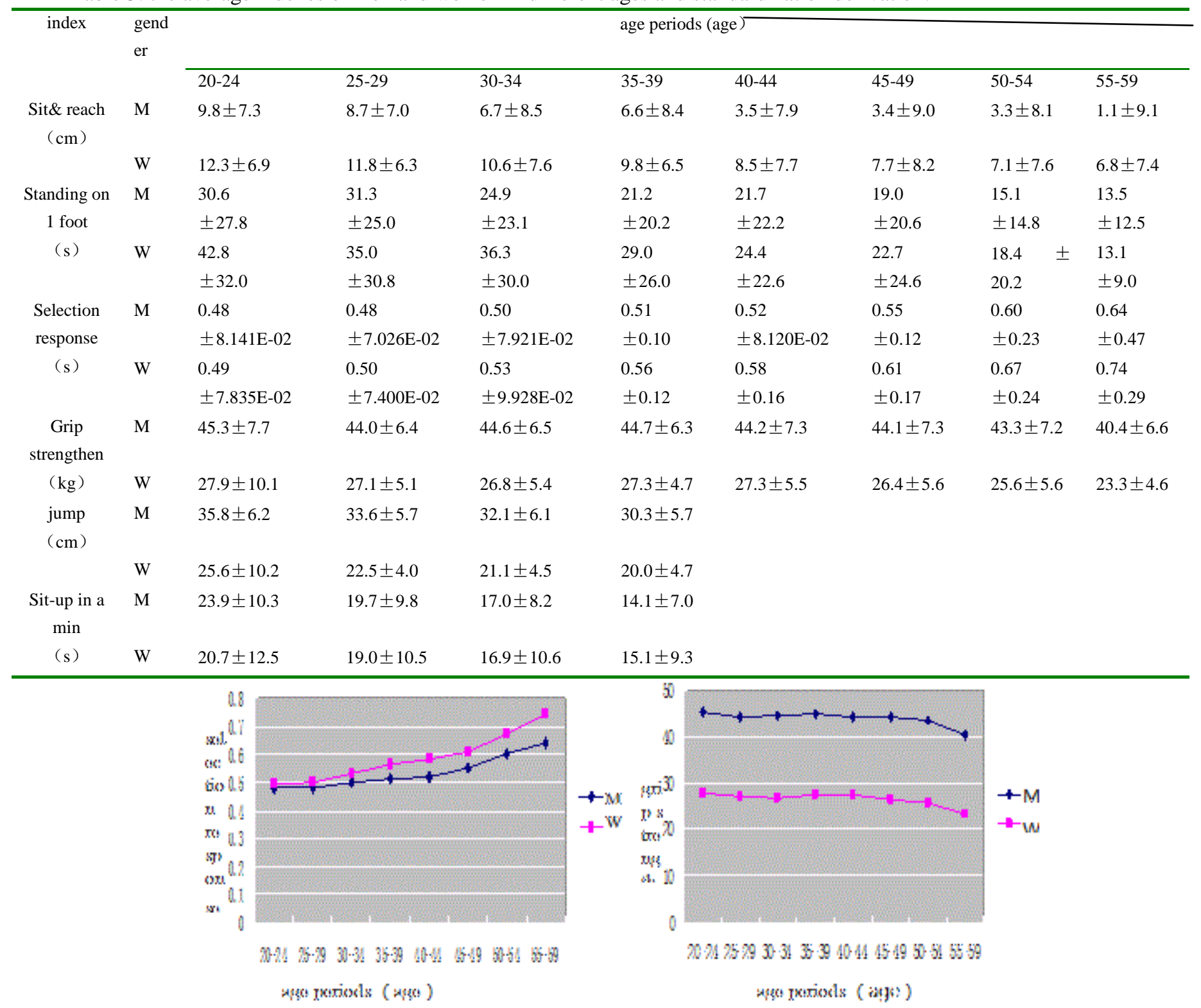

Fig. 7 comparisons of average selection responses of men and women in different age periods

A vertical jump or vertical leap is the act of raising one's center of gravity higher in the vertical plane solely with the use of one's own muscles; it is a measure of how high an individual or athlete can elevate off the ground from a standstill. Vertical jump measurements are used primarily in athletic circles both to measure performance and as something athletes brag about among themselves. The sit-up is a strength training exercise commonly performed with the aim of strengthening the hip flexors and abdominal

Fig. 8 comparisons of average grip strength of men and women in different age periods

muscles. It begins with lying with the back on the floor, typically with the arms across the chest or hands behind the head and the knees bent in an attempt to reduce stress on the back muscles and spine, and then elevating both the upper and lower vertebrae from the floor until everything superior to the buttocks is not touching the ground. Some argue that sit-ups can be dangerous due to high compressive lumbar load and may be replaced with the crunch in exercise programs. 


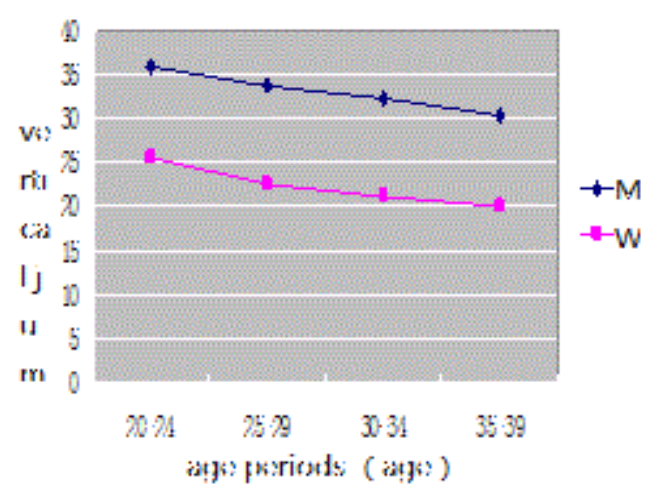

Fig. 9: comparisons of average vertical jump of men and women in different age periods

4. Conclusions.

1) The heights of adult males and females in Xi'an City decreases with the increase of the age; the weight of the men reaches the maximum at the age of 40-44.

2) The average vital captivity of men is higher than that of women at all ages.

3) As for sit-up, standing on one foot, selection response and one-minute sit-up, the averages of women are higher than those of men. The grip strengths and vertical jumps of men are higher than those of women.

\section{Suggestions.}

In order to further improve the fitness awareness, and enlarge the population strengthen of national fitness; strengthen the fitness knowledge and the training methods. Increase the fitness square and improve the fitness machines. Carry out all kinds of national fitness activities and have the goal of increasing the physical fitness reached.

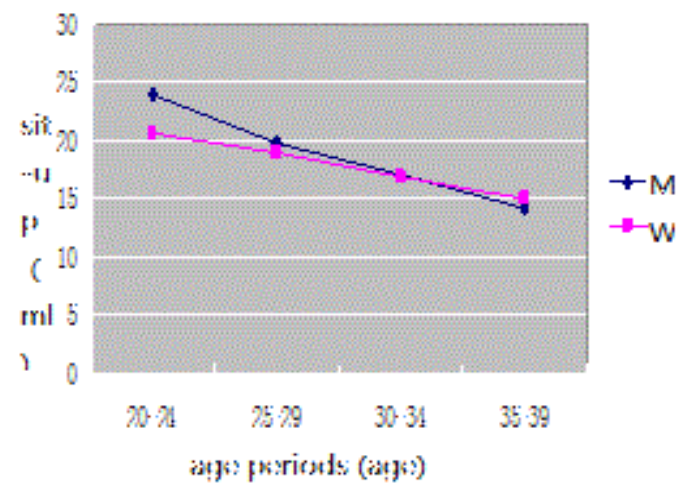

Fig. 10: comparisons of average sit-up in a minute of men and women in different age periods

\section{References}

[1]. Department of Sports in Shenzhen City. The research and application of the national body condition assessment in Shenzhen City [M]. Shenzhen: Haitian Publishing House, 2005

[2]. General Administration of Sport, overall ministry community, national physical quality monitoring center. The national physical quality monitoring work manual in 2000 [S], 2000.

[3]. General Administration of Sport, standardization manual of national adult physical quality monitoring in China [M].Beijing: China Standardization Press.1996.

[4]. Department of Sports in Shenzhen City. National physical quality research in Shenzhen [M]. Beijing : Beijing Sport University Press, 2005 